EXTENDED REPORT

\title{
Physiological levels of hydrocortisone maintain an optimal chondrocyte extracellular matrix metabolism
}

\author{
J Wang, D Elewaut, I Hoffman, E M Veys, G Verbruggen
}

Ann Rheum Dis 2004;63:61-66. doi: 10.1136/ard.2002.005298

\begin{abstract}
See end of article for authors' affiliations

Correspondence to: Dr G Verbruggen, Polikliniek Reumatologie, OK12, Universitair Hospitaal, De Pintelaan, 185, B-9000 Ghent, Belgium; gust.verbruggen@ rug.ac.be
\end{abstract}

Accepted 28 April 2003

\begin{abstract}
Objective: To investigate the effects of physiological doses of hydrocortisone on synthesis and turnover of cell associated matrix (CAM) by human chondrocytes obtained from normal articular cartilage.

Methods: Human articular cartilage cells were obtained from visually intact cartilage of the femoral condyles of five donors and maintained in culture for one week to reach equilibrium in accumulated CAM compounds. $0,0.05,0.20$, and $1.0 \mu \mathrm{g} / \mathrm{ml}$ hydrocortisone was added to the nutrient media during the entire culture period. Cells were liberated and levels of CAM aggrecan, type Il collagen, and fibronectin, of intracellular IGF-1, IL $1 \alpha$ and $\beta$, and of their respective plasma membrane bound receptors IGFRI, ILIRI, and the decoy receptor ILIRII, were assayed by flow cytometry.

Results: In comparison with controls, hydrocortisone treated chondrocytes, at all concentrations, expressed significantly higher plasma membrane bound IGFRI. Intracellular IGF-1 levels remained unchanged. Together with these changes, reflecting an increased ability to synthesise extracellular matrix (ECM) macromolecules, hydrocortisone treated cells expressed significantly higher amounts of the plasma membrane bound decoy ILIRII. Concurrently, intracellular ILI $\alpha$ and $\beta$ levels and membrane bound ILIRI were down regulated. Levels of CAM aggrecan, type II collagen, and fibronectin were significantly up regulated in the chondrocytes treated with hydrocortisone.

Conclusion: $0.05 \mu \mathrm{g} / \mathrm{ml}$ hydrocortisone treated chondrocytes had decreased catabolic signalling pathways and showed an enhanced ability to synthesise ECM macromolecules. Because IL1 activity was decreased and the expression of ILIRII decoy receptor enhanced, more of the ECM macromolecules produced remained accumulated in the CAM of the chondrocytes. The effects were obtained at doses comparable with physiological plasma levels of hydrocortisone in humans.
\end{abstract}

A side from the up regulation of local tissular "inflammatory" pathways, a variable degree of inflammation can occur in the synovium of osteoarthritic joints. This tissue is then invaded by lymphomyeloid cells, some of which produce the catabolic cytokines that are extremely harmful for the joint tissues. Intra-articular injections of corticosteroids effectively alleviate the pain caused by local inflammation in synovial joints. Therefore, in osteoarthritis (OA), mainly during episodes of inflammatory exacerbations, local administration of glucocorticoid hormones is common practice.

Disagreement among doctors has long existed about the physiological and/or toxic effects of corticosteroids on articular cartilage. Most early in vivo experiments showed that corticosteroids, especially after intra-articular administration, may provoke or worsen cartilage lesions. ${ }^{1-9}$ However, a systematic review of these reports shows that degeneration of articular cartilage, resulting from steroid administration, occurred after the administration of unrealistically high doses of this hormone. Similarly, Charcot-like arthropathy has been reported in man after a series of about 20 intra-articular injections of steroids. ${ }^{70}$ The suppression, by supraphysiological doses of glucocorticoids, of aggrecan and type II collagen synthesis rates in cartilage explant cultures from different origin ${ }^{11-13}$ is a possible explanation for the failure of the cartilage cell repair function after administration of steroids. The deleterious effects on articular cartilage as previously reported may, however, have been provoked by local inflammatory reactions ${ }^{14}{ }^{15}$ after repeated administration of insoluble crystalline preparations with prolonged action. ${ }^{78} 16$

More recently, and in contrast with the older observations, single or intermittent local or systemic administration of physiological doses of corticosteroids in different models of experimentally induced OA showed that these drugs had a protective effect on osteoarthritic cartilage-for example, in the meniscectomised rabbit model, ${ }^{17}{ }^{18}$ in the chemically induced cartilage damage in the guinea pig, ${ }^{19}$ and in the Pound-Nuki dog model of OA. ${ }^{20} 21$ Despite the presence of possible species differences, these drugs had similar protective effects on the osteoarthritic cartilage of human patients. ${ }^{22}$

Different mechanisms can underlie the chondroprotective effects of corticosteroids in vivo. Glucocorticoids inhibit the infiltration of lymphomyeloid cells in the synovium, and thus reduce the release of cytokines and suppress their effects on the neighbouring joint tissues. ${ }^{23}$ The protective effect of the treatment was also ascribed to the ability of glucocorticoids and other steroid hormones, at physiological doses, to stimulate the synthesis and/or to inhibit the degradation of the extracellular matrix (ECM) of articular cartilage, as shown in cartilage explant cultures. ${ }^{24-26}$ Probably, inhibition of the degradation of the ECM was due to the ability of these hormones to reduce pathological neutral protease activity in both cartilage and synovium. $.^{21} 227-29$

These anabolic and anti-catabolic effects of glucocorticosteroids on cartilage might be the consequence of an effect of steroid hormones on some of the important chondrocyte

\footnotetext{
Abbreviations: CAM, cell associated matrix; DMEM, Dulbecco's modified Eagle's medium; ECM, extracellular matrix; FCS, fetal calf serum; FITC, fluorescein isothiocyanate; HBSS, Hanks's balanced salt solution; IGF-1, insulin-like growth factor 1; IGFR 1, insulin-like growth factor receptor 1; IL, interleukin; ILIR, interleukin 1 receptor; mÂb, monoclonal antibodies; MFI, mean fluorescence intensity; OA, osteoarthritis; PBS, phosphate buffered saline; PE, phycoerythrin
} 
autocrine/paracrine metabolic pathways. Hydrocortisone has been reported to act synergistically with different essential growth and differentiation factors to affect the synthesis of the ECM ground substance. ${ }^{30-32}$ In addition, glucocorticosteroids might directly affect the synthesis of the ECM because the in vitro effects of these hormones have been shown to occur in the absence of serum. ${ }^{26}{ }^{33}$

Our study was undertaken to investigate the metabolic effects of physiological doses of hydrocortisone on ECM metabolism of human chondrocytes isolated from normal articular cartilage.

\section{MATERIAL AND METHODS Isolation of articular chondrocytes}

Human articular chondrocytes were isolated as described elsewhere, ${ }^{34}$ with a few modifications. ${ }^{35}$ Briefly, human articular cartilage was obtained at necropsy from femoral condyles of five different donors (four men, one woman, age range $18-80$ years) within 24 hours post mortem. All donors had died after a short illness. None of them had received corticosteroids or cytostatic drugs. Visually intact cartilage was harvested and prepared for culture. Cartilage removed from the femoral condyles was diced into small fragments and the chondrocytes were isolated by sequential enzymatic digestion (hyaluronidase, pronase, and collagenase) of the ECM as described in detail. ${ }^{35}$ Isolated cells were then centrifuged for 10 minutes at $1500 \mathrm{rpm}$, washed three times in Dulbecco's modified Eagle's medium (DMEM) with 10\% fetal calf serum (FCS), tested for viability (trypan blue exclusion test), and counted. More than $95 \%$ of the cells were usually viable after isolation.

\section{Cultures in alginate gel}

Chondrocyte cultures in alginate beads were prepared as described elsewhere, ${ }^{36}$ with some modifications. Chondrocytes suspended in one volume double concentrated Hanks's balanced salt solution without calcium and magnesium (HBSS; Gibco) were carefully mixed with an equal volume of $2 \%$ alginate (low viscosity alginate from Macrocystis pyrifera; Sigma) in HBSS, and autoclaved for 15 minutes. The final cell concentration was $5 \times 10^{6}$ chondrocytes per $\mathrm{ml}$ in $1 \%$ alginate. The chondrocyte/alginate suspension was then slowly dripped through a 23 gauge needle into a $102 \mathrm{mM}$ calcium chloride solution. The beads were allowed to polymerise for 10 minutes at room temperature. The calcium chloride was then removed, the beads were washed three times with $0.15 \mathrm{M}$ sodium chloride and, finally, maintained in a six well plate with $1 \times 10^{6}$ cells per culture (each well containing 20 alginate beads; \pm 50000 chondrocytes per bead) in $4 \mathrm{ml}$ of DMEM with $10 \%$ FCS and $50 \mu \mathrm{g}$ ascorbate per $\mathrm{ml}$ in an incubator at $37^{\circ} \mathrm{C}$ under $5 \% \mathrm{CO}_{2}$. The nutrient medium was replaced twice weekly for seven days. Recently, we showed that ECM metabolism by chondrocytes reached steady state after one week in this alginate culture system. ${ }^{37}$

\section{Effect of hydrocortisone on the expression of ECM molecules and on intracellular cytokine and growth factor levels}

The chondrocytes were cultured in DMEM supplemented with $10 \%$ FCS and increasing amounts $(0,0.05,0.20$, and $1.0 \mu \mathrm{g} / \mathrm{ml}$ ) of hydrocortisone during the entire seven day culture period. Hydrocortisone was used because it is the physiologically occurring glucocorticoid and was used as a solution of hydrocortisone sodium succinate in phosphate buffered saline (PBS) with benzyl alcohol q.s. (Solucortef, Upjohn). The contents of the vials were diluted to the desired concentrations of 0.05 to $1.0 \mu \mathrm{g} / \mathrm{ml}$.

\section{Preparation of chondrocytes for flow cytometry}

After seven days of culture the nutrient media of the chondrocyte cultures were removed. The alginate beads were washed and dissolved by incubation for 10 minutes with $3 \mathrm{ml}$ of $55 \mathrm{mM}$ trisodium citrate dihydrate $\mathrm{pH} 6.8$ and $0.15 \mathrm{M} \mathrm{NaCl}$ at $25^{\circ} \mathrm{C}$. The resulting suspension was centrifuged at $1500 \mathrm{rpm}$ for 10 minutes to separate cells with their cell associated matrix $(\mathrm{CAM})^{35} 38$ from the constituents of the interterritorial matrix. The pellet with the chondrocytes was recovered to assess the CAM macromolecule contents, the plasma membrane bound receptors, and the intracellular levels of cytokines and growth factors.

Insulin-like growth factor receptor 1 (IGFRl), interleukin 1 receptors I and II (ILIRI and -II) on the cell membrane, and aggrecan, type II collagen, and fibronectin in the CAM were tested directly after incubation with the appropriate antibodies for 30 minutes in the dark at $4^{\circ} \mathrm{C} .20 \mu \mathrm{l}$ of $50 \mu \mathrm{g} / \mathrm{ml}$ fluorescein isothiocyanate (FITC) labelled antibodies was used to react with $2 \times 10^{5}$ cells resuspended in $100 \mu \mathrm{l}$ PBS. To evaluate the expression of IGF-1, ILl $\alpha$ and $\beta$ inside the cells, chondrocytes were permeabilised with a Cytofix/Cytoperm Plus Kit (PharMingen, San Diego, CA, USA) according to the manufacturer's instruction. Briefly, cells in culture were incubated with monensin (GolgiStop, $4 \mu \mathrm{l} / 6 \mathrm{ml}$ medium) for five hours to block the protein transport from Golgi apparatus. Cells isolated from alginate were then permeabilised with Cytofix/Cytoperm solution for 20 minutes. After a wash in $1 \times$ Perm/Wash solution, the cells were incubated with monoclonal antibodies $(\mathrm{mAb})$.

\section{Antibodies used for flow cytometry}

Mouse antihuman mAb (subclass: IgGl) against IGFRl, ILIRI, ILIRII, ILI $\beta$, and the mouse IgGl negative control were purchased from R\&D systems (Abingdon, United Kingdom; IGFR1: clone 33255.111; IL1RI: clone 35730.111; ILIRII: clone 34141.11; ILI $\beta$ : clone 8516.311). Mouse antihuman IGF-l and ILl $\alpha$ mAb were purchased from Biosource Europe (Nivelles, Belgium; IGF-1: clone AHG0014; ILl $\alpha$ : clone 624B3F2). Polyclonal antifibronectin rabbit IgG were obtained from Chemicon International (Harrow, UK). Mouse antihuman chondrocyte-specific aggrecan mAb (clone 4D112A9; Biosource Europe) were shown to react specifically with the Gl domain of the invariable hyaluronan binding region of the human aggrecan molecule, and were used to detect the aggrecan in the chondrocyte CAM. Mouse antihuman type II collagen mAb (clone II-4C11; ICN Biochemicals, Ohio, USA) were chosen to detect type II collagen. All the antibodies (except aggrecan and type II collagen) were conjugated with FITC (isomer I; Sigma-Aldrich, Belgium) as previously described. $^{38}$ The anti-aggrecan and type II collagen mAb were conjugated with phycoerythrin (PE; Sigma-Aldrich) as described. ${ }^{39}$ The conjugated $\mathrm{mAb}$ were used in a direct immunofluorescent staining protocol for flow cytometry. Appropriate FITC or PE labelled isotype matched mouse or rabbit IgGl (Becton Dickinson: clone $\times 40$ ) were used as a negative control.

\section{Flow cytometric analysis}

Stained cells were analysed on a flow cytometer (FACSort; Becton Dickinson, San Jose, CA, USA) with CELLQuest software. From each sample, 15000 events were analysed. Cells were gated on forward and side scatter to exclude dead cells, debris, and aggregates. Propidium iodide was additionally used to exclude dead cells when the epitopes outside the cells-that is, IGFR1, ILIRI and -II, and ECM molecules, were analysed. ${ }^{38}{ }^{40}$ The mean fluorescence intensity (MFI) of the positive cell population, which is due to the binding of the conjugated antibodies, was used to quantify the presence of IGFRI, ILIRI and -II on the plasma membrane, the presence 
of the ECM molecules in the CAM, and the accumulation of IGF- 1, ILl $\alpha$ and $\beta$ inside the cells. MFI values were obtained by subtraction of the MFI of the negative control population from the MFI of the positive stained population. For comparison between experiments the Quantum Simply Cellular Microbead Kit (Sigma) was used to calibrate the fluorescence scale of the flow cytometer. The product contains a mixture of four uniform microbead populations, which differ by their incremental abilities to bind mouse IgG. The microbeads were stained and processed in parallel with the cell samples using the same amount of FITC labelled antibodies and incubation time. The fluorescence scale of the cytometer was adapted before every experiment in order to keep identical MFIs for the four peaks of the calibration beads. The MFI of cell samples was then analysed without changing any instrument settings.

\section{Statistics}

MFI values for the different parameters in each of the donor chondrocytes were calculated from triplicate cell cultures. These MFI values were used to generate median values for each variable in the group of five donors. The Wilcoxon rank sum test for paired samples was used to analyse the changes in these groups. The MFI values in the untreated controls were then normalised to 100 to allow percentage changes after the exposure to different concentrations of hydrocortisone to be presented. Paired Student's $t$ tests were used to test significance and to study the effect sizes of the changes in the chondrocyte cultures after hydrocortisone treatment. Significance levels for all tests were set at $\mathrm{p}=0.05$.

\section{RESULTS}

Table 1 presents the real MFI values for CAM macromolecules, the plasma membrane bound receptors, and the intracellular levels of cytokines and growth factors in controls and in hydrocortisone treated chondrocyte cultures. Percentage changes in chondrocyte fluorescence intensity with hydrocortisone are given in the figures.

\section{Factors promoting synthesis and accumulation of} ECM: IGF-1/IGFR 1 autocrine pathway and IL IRII

In comparison with controls, hydrocortisone treated chondrocytes expressed significant and dose related increases of plasma membrane bound IGFRl (fig 1A). On average, the IGFR1 levels increased by $25.6 \%, 30.7 \%$, and $37.0 \%$ at hydrocortisone doses of $0.05,0.2$, and $1.0 \mu \mathrm{g} / \mathrm{ml}$ of nutrient medium. The response to hydrocortisone did not level off at higher doses because each increase in the concentration of the test drug resulted in additional significant increases of the plasma membrane receptor levels. Intracellular IGF-1 levels remained unchanged after exposure to the steroid (fig 1B).
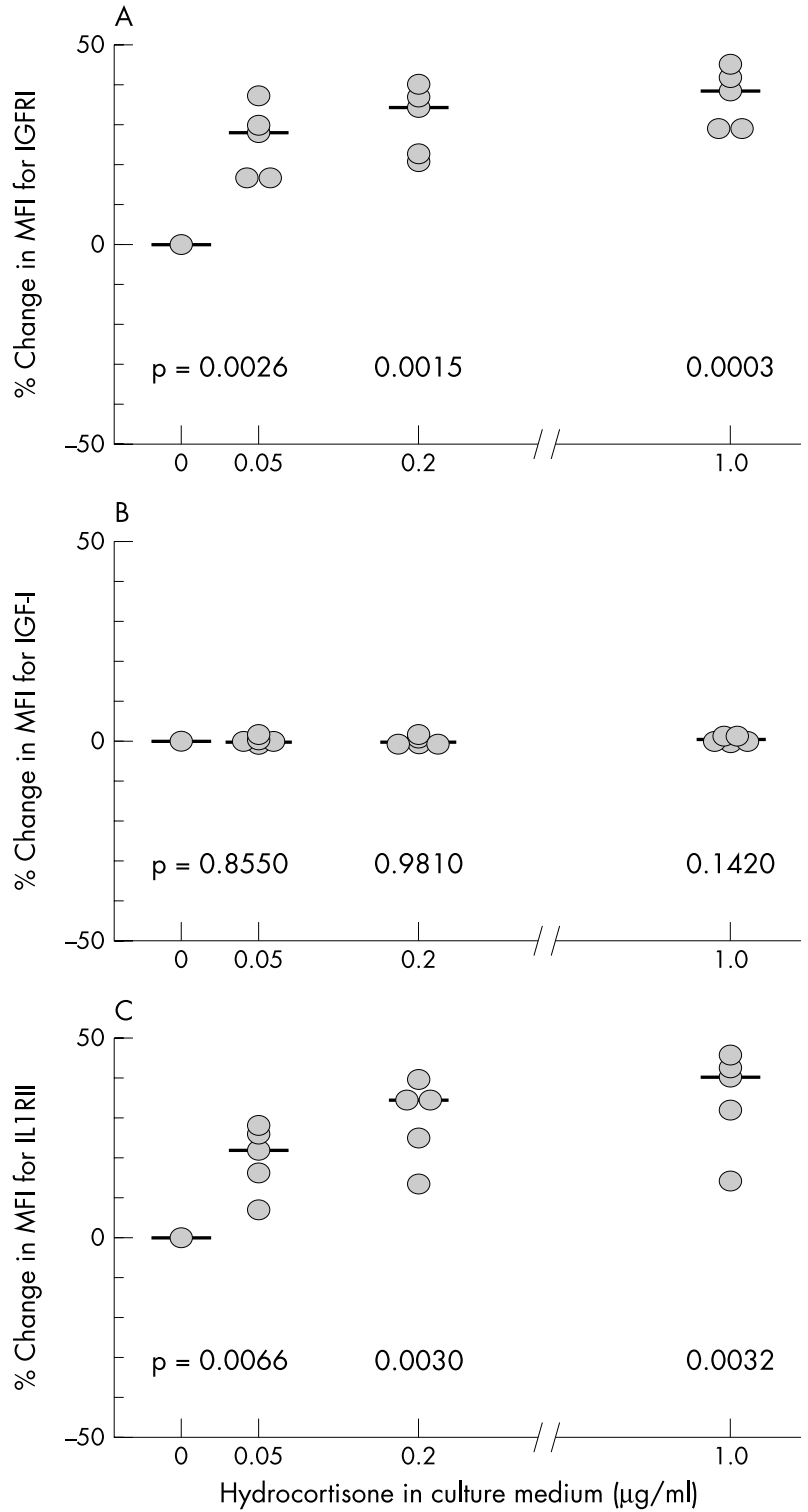

Figure 1 Effects of increasing doses of hydrocortisone on the IGF-1/ IGFRI autocrine pathway and on plasma membrane IL1RII. Percentage changes in chondrocyte MFI due to the binding of monoclonal antibodies specific for IGFRI (A), IGF-1 (B), and ILIRII (C) are shown for varying doses of hydrocortisone in the culture medium. Each dot represents the mean value of the three results obtained in a single donor. Median values are indicated for each dose of hydrocortisone. Results of paired samples $t$ test ( $p$ values) are given in the figure.

Table 1 MFI values for the factors of anabolic and catabolic pathways affecting ECM homoeostasis and CAM macromolecules

\begin{tabular}{llccc}
\hline & \multicolumn{3}{l}{ Hydrocortisone $(\mu \mathrm{g} / \mathrm{ml})$} & \\
\cline { 2 - 5 } & 0.00 & 0.05 & 0.20 & 1.00 \\
\hline IGF-1 & $55.2(35.4-61.9)$ & $55.2(35.4-61.1)$ & $55.5(35.1-61.3)$ & $55.3(35.7-61.6)^{*}$ \\
IGFR1 & $11.4(8.2-12.9)$ & $14.7(9.6-16.7)^{*}$ & $15.6(10.0-17.3)^{*}$ & $15.8(10.6-18.3)^{*}$ \\
ILIRII & $11.1(8.5-17.5)$ & $13.2(10.9-18.7)^{*}$ & $14.9(11.4-19.9)^{*}$ & $15.6(12.4-20.1)^{*}$ \\
IL1 $\alpha$ & $34.9(23.6-72.6)$ & $24.2(21.4-63.9)^{*}$ & $21.8(20.3-62.9)^{*}$ & $20.4(19.9-61.8)^{*}$ \\
ILI $\beta$ & $78.5(45.1-81.9)$ & $65.1(38.4-68.7)^{*}$ & $54.0(35.5-64.5)^{*}$ & $53.1(36.3-61.7)^{*}$ \\
ILIRI & $11.7(9.4-15.4)$ & $10.9(9.2-15.0)^{*}$ & $10.8(8.5-14.7)^{*}$ & $10.2(8.0-14.1)^{*}$ \\
Aggrecan & $41.8(28.3-57.9)$ & $96.3(41.8-118.8)^{*}$ & $114.9(53.0-180.1)^{*}$ & $118.8(61.1-187.9)^{*}$ \\
Collagen & $15.7(12.0-24.6)$ & $19.8(15.3-30.0)^{*}$ & $20.0(17.4-32.9)^{*}$ & $26.9(17.9-34.6)^{*}$ \\
Fibronectin & $221.5(193.8-522.2)$ & $363.7(252.3-633.7)^{*}$ & $454.1(261.9-84.9)^{*}$ & $545.8(304.8-793.1)^{*}$
\end{tabular}

Median MFI values, lower and upper ranges are given for the different variables under the influence of $0.00,0.05,0.20$, and $1.00 \mu \mathrm{g}$ of hydrocortisone per $\mathrm{ml}$ of nutrient medium.

*Wilcoxon rank sum test for paired samples, significant change compared with control, $p<0.05$. 
Along with these changes that reflected an increased capability of synthesising the appropriate ECM macromolecules, hydrocortisone treated cells expressed significantly higher amounts of plasma membrane bound decoy IL1RII. Percentage changes induced for this receptor were 19.9\%, $29.3 \%$ and $35.3 \%$, on average, at hydrocortisone culture medium levels of $0.05,0.2$, and $1.0 \mu \mathrm{g} / \mathrm{ml}$, respectively. Once more, each increase in the concentration of hydrocortisone in the culture medium resulted in an additional and significant increase of the expression of ILIRII (fig lC).

\section{Factors promoting degradation of ECM: IL I/IL IRI autocrine pathway}

Concurrently, intracellular ILl $\alpha$ and $\beta$ levels and membrane bound IL1RI were found to be down regulated after exposure of the chondrocytes to hydrocortisone.

Hydrocortisone treated chondrocytes showed significant and dose related decreases of intracellular ILl $\alpha$ and $\beta$. ILl $\alpha$ levels inside the cells on average decreased by $19.1 \%, 23.7 \%$, and $25.6 \%$, and ILI $\beta$ levels were reduced by $14.3 \%, 23.3 \%$, and $25.9 \%$ at hydrocortisone doses of $0.05,0.2$, and $1.0 \mu \mathrm{g} / \mathrm{ml}$ of nutrient medium, respectively (figs $2 \mathrm{~A}$ and $\mathrm{B}$ ). The response of ILl $\alpha$ to hydrocortisone did not level off at higher doses. Each increase in the concentration of the test drug resulted in a further significant decrease of this cytokine inside the chondrocyte. In contrast, the response of IL1 $\beta$ to hydrocortisone levelled off at $0.2 \mu \mathrm{g} / \mathrm{ml}$ of this steroid. Together with both isoforms of ILl, the expression of the signalling receptor of these catabolic cytokines, ILIRI, was down regulated on average by $3.8 \% \quad(p=0.017), 6.4 \%$ $(p=0.009)$, and $10.5 \%(p=0.003)$ of the baseline values at increasing doses of hydrocortisone (fig 2C).

\section{Cell associated matrix content}

The levels of CAM aggrecan, type II collagen, and fibronectin were significantly up regulated in the chondrocytes treated with hydrocortisone.

In comparison with controls, hydrocortisone treated chondrocytes expressed significant and dramatic dose related increases of CAM aggrecan. Aggrecan levels on average increased by $90.2 \%, 161.1 \%$, and $184.4 \%$ at $0.05,0.2$, and $1.0 \mu \mathrm{g} / \mathrm{ml}$ of hydrocortisone in the culture medium. Each increase in the culture medium levels of the drug provoked an additional significant increase in CAM aggrecan (fig 3A). Equally, hydrocortisone treated chondrocytes expressed significant and dose related increases of CAM type II collagen. These collagen levels on average increased by $27.0 \%, 37.8 \%$, and $59.4 \%$ at $0.05,0.2$, and $1.0 \mu \mathrm{g} / \mathrm{ml}$ of hydrocortisone in the culture medium. The response to hydrocortisone levelled off at $0.2 \mathrm{mg} / \mathrm{ml}$ of the drug in the medium, and a further increase in the concentration of the steroid did not cause an additional increase in CAM collagen (fig 3B). A similar response of the chondrocytes to the steroid was observed for CAM fibronectin. Increases of baseline values by $31.7 \%$, $47.2 \%$, and $70.7 \%$ at the test doses used were seen (fig 3C).

\section{DISCUSSION}

Contrasting results in previous experiments on cartilage explants may in part be due to the varying conditions of the existing ECM, the heterogeneity of chondrocyte populations in the different samples, and their different viability. These problems are avoided by the use of homogeneous cell populations of isolated chondrocytes in suspension culture. Chondrocyte culture in alginate gel is considered to be a valid system for studying both anabolism and catabolism of chondrocytes. $^{36}{ }^{41-43}$ Articular cartilage cells in this culture condition maintain their phenotype and synthesise cartilagespecific collagens and ECM aggrecans. ${ }^{36}{ }^{37}$ The culture model allowed in vivo chondrocyte phenotypes to be studied in
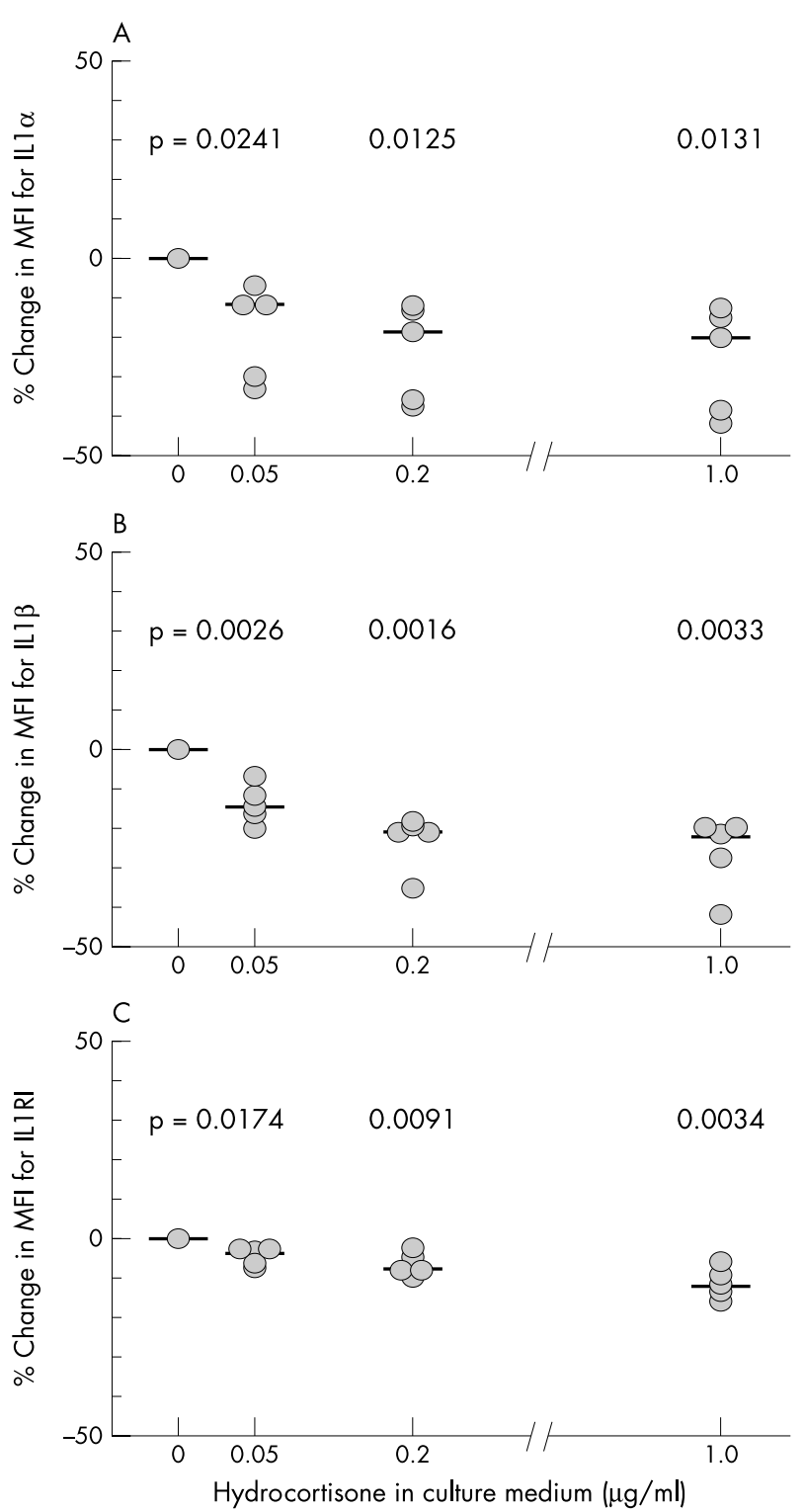

Figure 2 Effects of increasing doses of hydrocortisone on the ILI/ILIRI autocrine pathway. Percentage changes in chondrocyte MFI due to the binding of monoclonal antibodies specific for ILI $\alpha(A), I L 1 \beta$ (B), and ILIRI (C) are shown for varying doses of hydrocortisone in the culture medium. Each dot represents the mean value of the three results obtained in a single donor. Median values are indicated for each dose of hydrocortisone. Results of paired samples $t$ test ( $p$ values) are given in the figure.

laboratory conditions. Topographically dependent phenotypic expression of ECM compounds in joints, as well as the age related decline in the chondrocyte response to growth factors, was preserved when the chondrocytes were cultured in alginate beads. ${ }^{44}{ }^{45}$ The newly synthesised ECM compounds are assembled into a well ordered matrix as present in hyaline articular cartilage. ${ }^{36} 4142$ The advantage of alginate is the reversibility of the gelled condition of this matrix, allowing the study of the CAM surrounding the isolated chondrocytes. ${ }^{38-40}$

Our studies have shown that hydrocortisone treated chondrocytes, even at the lowest $0.05 \mu \mathrm{g} / \mathrm{ml}$ concentration, showed a significantly increased accumulation of CAM aggrecan, type II collagen, and fibronectin. This increased accumulation of CAM macromolecules obviously resulted from a decrease in the activity of the catabolic pathways 

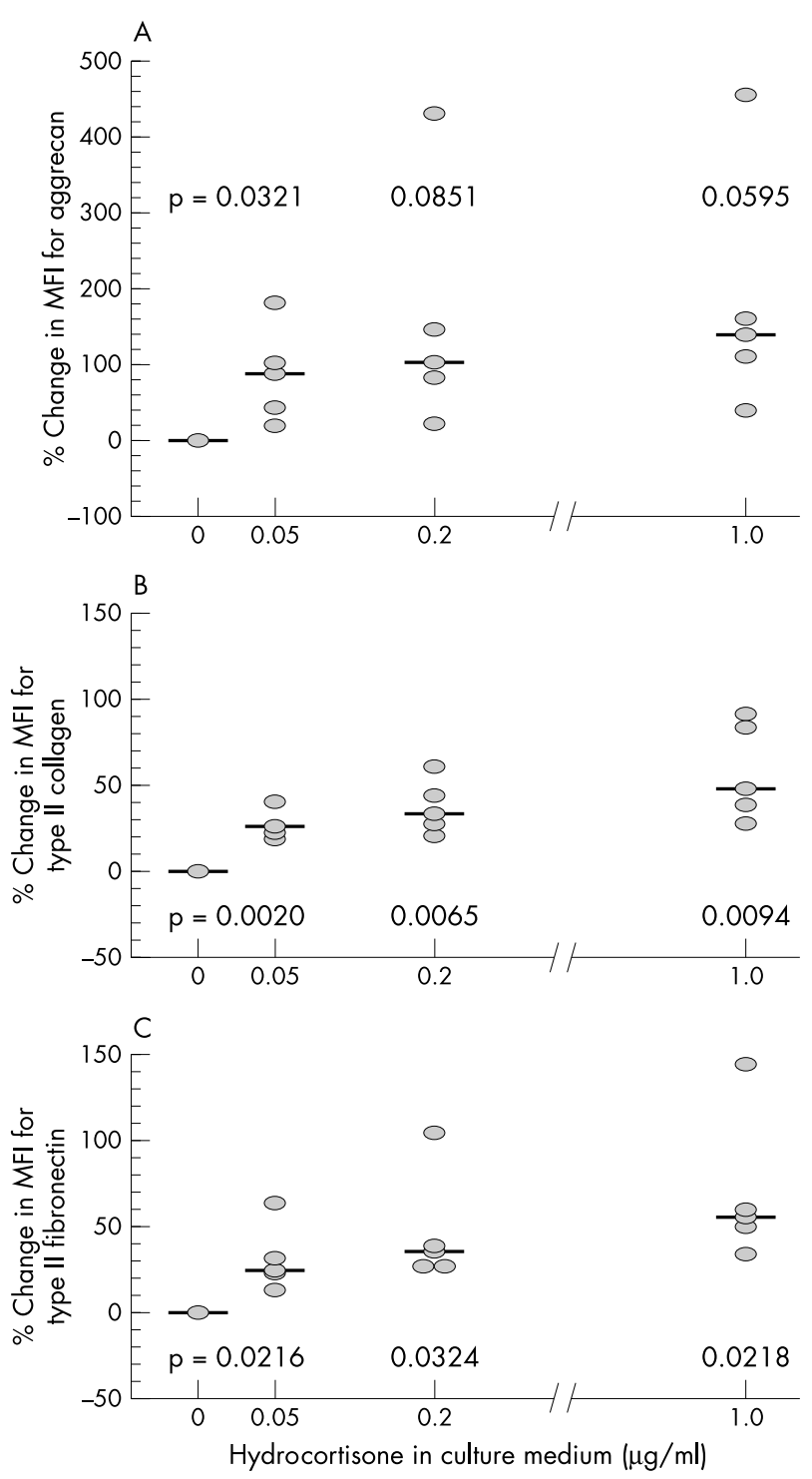

Figure 3 Effects of increasing doses of hydrocortisone on the levels of CAM aggrecan, type II collagen, and fibronectin. Percentage changes in chondrocyte MFI due to the binding of monoclonal antibodies specific for aggrecan (A), type II collagen (B), and fibronectin (C) are shown for varying doses of hydrocortisone in the culture medium. Each dot represents the mean value of the three results obtained in a single donor. Median values are indicated for each dose of hydrocortisone. Results of paired samples $t$ test ( $p$ values) are given in the figure.

because the intracellular levels of both ILl isoforms were depressed in chondrocytes after the exposure to hydrocortisone. The intracellular growth factors and cytokines represent a reservoir of biologically active agents, of which variable amounts are secreted in response to various stimuli. It can be expected that the intracellular amounts of these bioactive molecules predict their extracellular function. Further suppression of the ILl catabolic pathway was seen as the expression of the signalling ILIRI receptor decreased, and as the plasma membrane ILIRII decoy receptor levels increased concomitantly, on the cells exposed to hydrocortisone. The decreased activity of the ILl mediated catabolic pathways in hydrocortisone treated chondrocytes-as reported by others $^{46}$ - explains the well documented reduction of neutral protease activities in steroid treated osteoarthritic cartilage samples. ${ }^{21} 222729$ These studies, as well the results presented here, are in line with the observation that steroid hormones prevented the enzymatic degradation and depletion of ECM proteoglycan in a model of endotoxin mediated cartilage degradation ${ }^{47}$ and retarded the degradation and clearance of sulphated proteoglycans from condylar cartilage of newborn mice treated with steroid hormone. ${ }^{48}$

A functional IGF-1/IGFRl pathway is critical for the synthesis of a normal $\mathrm{ECM}^{31}$ and seems also to be essential for preservation of the components of this matrix. Too small an amount of IGF-1 can result in a suboptimal expression of the ILIRII decoy receptor and an uncontrolled activity of the catabolic ILl pathway. ${ }^{49}{ }^{50}$ As the experiments conducted here showed that hydrocortisone enhanced the expression of IGFRl on the cell membrane, it can be suggested that the cortisone treated chondrocytes are more susceptible to their own autocrine IGF stimuli, and therefore, synthesise more and higher molecular weight aggrecans.

As a result of both the enhanced ability to synthesise ECM macromolecules, and the decreased activity of the catabolic pathways, hydrocortisone treated chondrocytes showed significantly up regulated levels of CAM aggrecan, type II collagen, and fibronectin. Glucocorticoids thus play a part in the maintenance of homoeostasis and the integrity of normal and diseased articular cartilage. The effects were obtained at doses comparable with the physiological plasma levels of hydrocortisone in the human species. The evening and morning hydrocortisone plasma concentrations in humans are 0.05 and $0.2 \mu \mathrm{g} / \mathrm{ml}$, respectively. As reported earlier, ${ }^{51}$ higher doses failed to provoke additional effects. The results presented here show a fundamental role for physiological doses (that is, endogenous production) of corticoids in maintaining normal human chondrocyte metabolism.

It is as yet speculative to defend the use of steroids to protect cartilage in clinical conditions without obvious inflammation. It has been recognised that the same cytokines that are produced during inflammation also control ECM homoeostasis in normal and osteoarthritic cartilage and are produced by the chondrocytes themselves. ${ }^{52}{ }^{53}$ In osteoarthritic chondrocytes or cartilage, the up regulation of the catabolic ILl $\alpha$ and $\beta$ pathways has been reported ${ }^{17} 18$ and a correlation with the occurrence and the degree of OA pathology was noted for IL1 $\beta .^{52-54}$ The increased catabolic cytokine levels are embodied by well documented increases in metalloproteinase activities, which are higher in osteoarthritic cartilage than in morphologically normal cartilage from the same joint. ${ }^{54-57}$ If cartilage cells from osteoarthritic tissues needed higher steroid levels than the physiological levels to adequately revert to the anabolic condition, the exogenous administration of corticoids might be useful to protect cartilage in clinical conditions without obvious inflammation. The sensitivity of osteoarthritic cartilage cells to the effects of hydrocortisone has not yet been tested.

\section{ACKNOWLEDGEMENTS}

This work was supported by an FWO grant 3G013201 and in collaboration with the Institut de Recherches SERVIER.

\section{Authors' affiliations}

J Wang, D Elewaut, I Hoffman, E M Veys, G Verbruggen, Department of Rheumatology, Ghent University Hospital, Ghent, Belgium

\section{REFERENCES}

1 Salter RB, Gross A, Haal JH. Hydrocortisone arthropathy: an experimental investigation. Can Med Assoc J 1967;97:374-7.

2 Bentley G, Goodfellow JW. Disorganization of the knees following intraarticular hydrocortisone injections. J Bone Joint Surg Br 1969:51:498-502.

3 Moskowitz RW, Davis W, Sammarco J, Mast W, Chase SW. Experimentally induced corticosteroid arthropathy. Arthritis Rheum 1970;13:236-43.

4 Behrens F, Shepard N, Mitchell N. Alteration of rabbit articular cartilage by intra-articular injections of glucocorticoids. J Bone Joint Surg Am 1975;57:70-6. 
5 Murray RC, DeBowes RM, Gaughan EM, Zhu CF, Athanasiou KA. The effects of intra-articular methylprednisolone and exercise on the mechanical properties of articular cartilage in the horse. Osteoarthritis Cartilage 1998;6:106-14.

6 Higuchi M, Masuda T, Susuda K, Ishii S, Abe K. Ultrastructure of the articular cartilage after systemic administration of hydrocortisone in the rabbit: an electron microscopic study. Clin Orthop 1980;152:296-302.

7 Papacrhistou G, Anagnostou S, Katsorhis TK. The effect of intraarticular hydrocortisone injection on the articular cartilage of rabbits. Acta Orthop Scand 1997;68(suppl 275):132-4.

8 Lufti AM, Kosel K. Effects of intra-articularly administered corticosteroids and salicylates on the surface structure of articular cartilage. J Anat 1978; 127:393-402

9 Mankin HJ, Zarins A, Jaffe WL. The effect of systemic corticosteroids on rabbit articular cartilage. Arthritis Rheum 1972;15:593-9

10 Le Roy Steinberg C, Duthie RB, Piva AE. Charcot-like arthropathy following intra-articular hydrocortisone. JAMA 1962;181:851-4.

11 Silbermann M, von der Mark K, Maor G, van Menxel M. Dexamethasone impairs growth and collagen synthesis in condylar cartilage in vitro. Bone Miner 1987; 2:87-106.

12 Takagi Y, Bjornsson BT. Cortisol inhibits glycosaminoglycan synthesis in cultured rainbow trout cartilage. Gen Comp Endocrinol 1997;108:80-6.

13 McKenzie L, Horsburgh BA, Ghosh P, Taylor TKF. Effect of anti-inflammatory drugs on sulphated glycosaminoglycan synthesis in aged human articular cartilage. Ann Rheum Dis 1976;35:487-97

14 Eymontt MJ, Gordon GV, Schumacher HR, Hansell JR. The effects on synovia permeability and synovial fluid leukocyte counts in symptomatic osteoarthritis after intraarticular corticosteroid administration. J Rheumatol 1982;9:198-203

15 Gordon GV, Schumacher HR. Electron microscopic study of depot corticosteroid crystals with clinical studies after intra-articular injection. J Rheumatol 1979:6:7-14

16 Mankin HJ, Conger KA. The acute effect of intraarticular hydrocortisone on articular cartilage in rabbits. J Bone Joint Surg Am 1966;48:1383-8.

17 Colombo C, Butler M, Hickman L, Selwyn M, Chart J, Steinetz B. A new mode of osteoarthritis in rabbits. II. Evaluation of anti-osteoarthritic effects of selected antirheumatic drugs administered systemically. Arthritis Rheum 1983:26:1132-9.

18 Butler M, Colombo C, Hickman L, O'Byrne E, Steele R, Steinetz B, et al. A new model of osteoarthritis in rabbits. III. Evaluation of anti-osteoarthritic effects of selected drugs administered intraarticularly. Arthritis Rheum 1983;26:1380-6.

19 Williams JM, Brandt KD. Triamcinolone hexacetonide protects against fibrillation and osteophyte formation following chemically induced articular cartilage damage. Arthritis Rheum 1985;28:1267-74.

20 Pelletier JP Martel-Pelletier J. Protective effects of corticosteroids on cartilage lesions and osteophyte formation in the Pond-Nuki dog model of osteoarthritis. Arthritis Rheum 1989;32:181-93.

21 Pelletier JP, Mineau F, Raynauld JP, Woessner JF, Gunja-Smith Z, MartelPelletier J. Intraarticular injections with methylprednisolone acetate reduce osteoarthritic lesions in parallel with chondrocyte stromelysin synthesis in experimental osteoarthritis. Arthritis Rheum 1994;37:414-23.

22 Pelletier JP, Martel-Pelletier J, Cloutier JM, Woessner JF Jr. Proteoglycandegrading acid metalloproteinase activity in human osteoarthritic cartilage, and the effects of intraarticular steroid injections. Arthritis Rheum 1987:30:541-8.

23 van den Berg WB. Impact of NSAID and steroids on cartilage destruction in murine antigen induced arthritis. J Rheumatol 1991;18(suppl 27):122-3.

24 Pelletier JP, Cloutier JM, Martel-Pelletier J. In vitro effects of tiaprofenic acid, sodium salicylate and hydrocortisone on the proteoglycan metabolism of human osteoarthritic cartilage. J Rheumatol 1989;16:646-55.

25 Hill DJ. Effects of cortisol on cell proliferation and proteoglycan synthesis and degradation in cartilage zones of the calf costochondral growth plate in vitro with and without rat plasma somatomedin activity. J Endocrinol 1981:88:425-35

26 Takigawa M, Takano T, Nakagawa K, Sakuda M, Suzuki F. Hydrocortisone stimulation of proliferation and glycosaminoglycan synthesis in rabbit craniofacial chondrocytes in vitro. Arch Oral Biol 1988;33:893-9.

27 Pelletier JP, Martel-Pelletier J. Cartilage degradation by neutral proteoglycanases in experimental osteoarthritis. Suppression by steroids. Arthritis Rheum 1985;28:1393-1401.

28 Martel-Pelletier J, Cloutier JM, Pelletier JP. Neutral proteases in human osteoarthritic synovium. Arthritis Rheum 1986:29:1112-21.

29 McGuire MB, Murphy M, Reynolds JJ, Russel RGG. Production of collagenase and inhibitor (TIMP) by normal, rheumatoid and osteoarthritic synovium in vitro: effects of hydrocortisone and indomethacine. Clin Biol 1981;61:703-10.

30 Van Osch GJ, van der Veen SW, Verwoerd-Verhoef HL. In vitro redifferentiation of culture-expanded rabbit and human auricular chondrocytes for cartilage reconstruction. Plast Reconstr Surg 2001; 107:433-40.

31 Van der Kraan PM, Vitters EL, Postma NS, Verbunt J, van den Berg WB. Maintenance of the synthesis of large proteoglycans in anatomically intact murine articular cartilage by steroids and insulin-like growth factor I. Ann Rheum Dis 1993;52:734-41.
32 Itagane $Y$, Inada $\mathrm{H}$, Fujita K, Isshiki G. Interactions between steroid hormones and insulin-like growth factor-I in rabbit chondrocytes. Endocrinology $1991 ; 128: 1419-24$

33 van der Kraan PM, Vitters EL, Postma NS, Verbunt J, van den Berg WB. Maintenance of the synthesis of large proteoglycans in anatomically intact murine articular cartilage by steroids and insulin-like growth factor I. Ann Rheum Dis 1993;52:734-41.

34 Green WT Jr. Behaviour of articular chondrocytes in cell culture. Clin Orthop $1971 \cdot 75 \cdot 248-60$

35 Cornelissen M, Verbruggen G, Malfait AM, Veys EM, Broddelez C, De Ridder $L$. The study of representative populations of native aggrecan aggregates synthesized by human chondrocytes in vitro. J Tissue Culture Methods 1993;15:139-46.

36 Guo J, Jourdian GW, MacCallum DK. Culture and growth characteristics of chondrocytes encapsulated in alginate beads. Connect Tissue Res 1989;9:277-97.

37 Verbruggen G, Veys EM, Wieme N, Malfait AM, Gijselbrecht L, Nimmegeers J, et al. The synthesis and immobilisation of cartilage-specific proteoglycan by human chondrocytes in different concentrations of agarose. Clin Exp Rheumatol 1990;8:371-8.

38 Wang L, Verbruggen G, Almqvist KF, Elewaut D, Broddelez C, Veys EM. Flow cytometric analysis of the human articular chondrocyte phenotype. Osteoarthritis Cartilage 2001;9:73-84.

39 Kronick MN, Grossman PD. Immunoassay techniques with fluorescent phycobiliprotein conjugates. Clin Chem 1983;29:1582-6.

40 Wang L, Almqvist KF, Broddelez C, Veys EM, Verbruggen G. Evaluation of chondrocyte cell-associated matrix metabolism by flow cytometry. Osteoarthritis Cartilage $2001 ; 9: 454-462$

41 Häuselmann HJ, Aydelotte MB, Schumacher BL, Kuettner KE, Gitelis SH, Thonar EJ-MA. Synthesis and turnover of proteoglycans by human and bovine adult articular chondrocytes cultured in alginate beads. Matrix 1992;12:116-29.

42 Häuselmann HJ, Fernandes RJ, Mok SS, Schmid TM, Block JA, Aydelotte MB, et al. Phenotypic stability of bovine articular chondrocytes after long-term culture in alginate beads. J Cell Sci 1994:107:17-27.

43 Lemare F, Steimberg N, Le Griel C, Demignot S, Adolphe M. Dedifferentiated chondrocytes cultured in alginate beads: restoration of the differentiated phenotype and of the metabolic responses. J Cell Physiol 1998;176:303-13.

44 Little CB, Ghosh P. Variation in proteoglycan metabolism by articular chondrocytes in different joint regions is determined by post-natal mechanical loading. Osteoarthritis Cartilage 1997;5:49-62

45 Loeser RF, Shanker G, Carlson CS, Gardin JF, Shelton BJ, Sonntag WE. Reduction in the chondrocyte response to insulin-like growth factor 1 in aging and osteoarthritis: studies in a non-human primate model of naturally occurring disease. Arthritis Rheum 2000;43:2110-20.

46 Lee SW, Tsou AP, Chan H, Thomas J, Petrie K, Eugui EM, et al. Glucocorticoids selectively inhibit the transcription of the interleukin 1 beta gene and decrease the stability of interleukin 1 beta mRNA. Proc Natl Acad Sci USA 1988;85:1204-8.

47 Hubbard JR, Mattmueller DR, Steinberg JJ, Poppas DP, Sledge CB. Effect of steroid hormones on endotoxin-mediated cartilage degradation. Mol Cell Biochem 1988:79:31-7.

48 Weiss A, Raz E, Silbermann M. Effects of systemic glucocorticoids on the degradation of glycosaminoglycans in the mandibular condylar cartilage of newborn mice. Bone Miner 1986;1:335-46.

49 Wang J, Elewaut D, Veys EM, Verbruggen G. IGF-1-induced IL-1RII overrules IL-1 activity and controls the homeostasis of the extracellular matrix of phenotypically stable human chondrocytes from normal cartilage. Arthritis Rheum 2003;48:1281-91

50 Wang J, Veys EM, Verbruggen G. Homeostasis of the extracellular matrix by human chondrocytes obtained from normal cartilage. Osteoarthritis Cartilage $2001 ; 9$ (suppl B):S30-1.

51 Almqvist KF, Wang L, Broddelez C, Verdonk R, Veys EM, Verbruggen G. The influence of hydrocortisone on aggrecan metabolism in human articular chondrocyte cultures: comparison of two different matrices. Clin Exp Rheumatol 2000:18:665-73.

52 Chambers MG, Bayliss MT, Mason RM. Chondrocyte cytokine and growth factor expression in murine osteoarthritis. Osteoarthritis Cartilage 1997:5:301-8.

53 Moos V, Fickert S, Muller B, Weber U, Sieper J. Immunohistological analysis of cytokine expression in human osteoarthritic and healthy cartilage. $J$ Rheumatol 1999;26:870-9.

54 Shlopov BV, Gumanovskaya ML, Hasty KA. Autocrine regulation of collagenase 3 (matrix metalloproteinase 13) during osteoarthritis. Arthritis Rheum 2000;43:195-205.

55 Pelletier JP, Martel-Pelletier J, Howell DS, Ghandur-Mnaymneh L, Enis JE, Woessner JF Jr. Collagenase and collagenolytic activity in human osteoarthritic cartilage. Arthritis Rheum 1983:26:63-8.

56 Okada Y, Shinmei M, Tanaka O, Naka K, Kimura A, Nakanishi I, et al. Localization of matrix metalloproteinase 3 (stromelysin) in osteoarthritic cartilage and synovium. Lab Invest 1992;66:680-90.

57 Arner EC, Tortorella MD. Signal transduction through chondrocyte integrin receptors induces matrix metalloproteinase synthesis and synergizes with interleukin-1. Arthritis Rheum 1995;38:1304-14. 